\title{
EKSPERIENTAL LEARNING PELATIHAN FINANCIAL LIFE SKILLS PADA MAHASISWA UNIVERSITAS MERDEKA MALANG
}

Submitted Date :

4 Nopember 2019

Accepted Date :

22 Nopember 2019
Aris Siswati

Universitas Merdeka Malang

aris.siswati@unmer.ac.id

\section{Suggested Citation:}

Siswati. Aris. 2019. Eksperintal Learning Financial Life Skills Pada Mahasiswa Universitas Merdeka Malang. Jurnal Bisnis dan Manajemens, Volume 6 No 1,: $\mathrm{xx}-\mathrm{xx}$.

Abstract:

The research is based on the strategic research plan of the Merdeka University of Malang which is included in the entrepreneurship category. The study aims to obtain an overview of Financial Life Skills in college students. The study was attended by 24 students from the Merdeka University of Malang Faculty of Economics and Business. Based on the research results, it can also be seen that there are real differences between before and after Financial Life Skills training. This shows the importance of Financial Life Skill training to improve the competitiveness of Merdeka Malang University graduates. FLS training not only provides investment knowledge but also knowledge and attitudes that can support when students graduate and enter the workforce. Armed with life skills and financial literacy obtained through training can be used as a guide and direction in treading a career ahead

Keyword : Experimental Learning, Financial Life Skills, Financial Literacy, Life Skills

\section{Abstrak:}

Penelitian didasarkan pada rencana strategis induk penelitian Universitas Merdeka Malang yang masuk dalam kategori kewirausahaan. Penelitian memiliki tujuan yang spesifik untuk memperoleh sebuah gambaran mengenai Financial Life Skills khususnya pada mahasiswa peserta pelatihan. Penelitian diikuti oleh mahasiswa Fakultas Ekonomi Bisnis Universitas Merdeka Malang sejumlah 24 orang. Berdasarkan penelitian dapat dilihat terjadi perbedaan yang nyata antar sebelum dan sesudah pelatihan Finansial Life Skill. Hal ini menunjukkan pentingnya adanya pelatihan Financial Life Skill guna meningkatkan daya saing lulusan Universitas Merdeka Malang. Pelatihan FLS tidak hanya memberikan pengetahuan investasi tetapi juga pengetahuan dan sikap yang bisa mendukung saat mahasiswa lulus dan memasuk dunia kerja. Dengan bekal skill ketrampila hidup dan literasi keuangan yang didapat melalui pelatihan bisa dijadikan pedoman dan arahan dalam menapaki karir kedepan

Kata Kunci : Eksperiental Learning, Financial Life Skills, Keterampilan Hidup, Literasi Keuangan 


\section{Pendahuluan}

Kualitas SDM khususnya generasi muda merupakan hal yang utama yang perlu mendapat perhatian, hal ini disebabkan generasi muda memainkan fungsi yang strategis di suatu negara, generasimuda sebagai jiwa penggerak reformasi yang akan memegang tongkat kepemimpinan di masa mendatang dan menjadi inisiator terbentuknya pembangunan perekonomian negara tangguh. Generasi muda Indonesia wajib mempunyai mental yang baik dan diringi memiliki kemandirian secara finansial.

Seiring dengan pola pikir menganai generasi yang akan datang, maka Pemuda Indonesia khususnya lulusan sarjana harus dipersiapkan dari jauh jauh hari dengan tepat dan sesuai perkembangan jaman. Generasi muda Indonesia harus memiliki ilmu pengetahuan, profesionalitas, sikap, serta keterampilan dan keahlian di dunia kerja yang baik, sehingga mampu bersaing pada dunia internasional. Berdasarkan laporan Asian Development Bank yang dirilis tahun 2017, masih banyak generasi muda Indonesia mendapatkan penghasilan tiap hari kurang dari Rp.28.000. Tantangan dan masalah di bidang social dan ekonomi yang harus dilalui oleh generasi muda rentan dan prasejahtera, termasuk perempuan dan difabilitas, telah memposisikan Indonesia tertinggal jauh dibandingkan negara Asian lainya.

Lulusan Sarjana mayoritas memiliki keterampilan finasial dan kecakapan hidup yang kurang sehingga yang akan sulit untuk membantu mengelola masalah finansial mereka, yang utama berfokus pada memperkuat kesiapan memasuki dunia pekerjaan dan meningkatkan standar kehidupan menjadi lebih baik. Semua orang di dunia berhak memperoleh sebuah peluang untuk menemukan penghidupan yang cukup dan layak bagi diri dan dan orang di sekitarnya.

Dengan USAID sebagai inisator bermitra dengan Pemerintah Republik Indonesia dan pihak swasta membekali lebih dari ratusan ribu anak muda dari klaster marginal secara ekonomi dan rentan, serta berkebutuhan khusus yang memiliki usia dibawah 35 tahun dengan keterampilan dan sumber daya yang diperlukan untuk berkompetisi di pasar kerja Indonesia maupun global. Fenomena yang berkembang saat ini pada kelompok pemuda sekarang antara lain; lemahnya kompetensi diri untuk kesiapan memasuki dunia kerja (seperti menentukan target, kerja dengan orang lain, berpikir kritis dan relevan, kehandalan untuk menyelesaikan kerja, komunikasi interpersonal). Bila dilihat dari sisi Sektor finansial; belum optimalnya keterampilan membuat keputusan keuangan yang sehat dan sesuai (seperti menabung, menganggarkan pembiayaan, manajemen tunai, penggunaan kredit). Youthwin Thorough Economic Participation (YEP) yang merupakan bagian dari United States Agency for International Development bekerja sama dengan Mitra pelaksana pelatihan finansial life skills agar dapat memenuhi kriteria (1) Memfokuskan pada "upgrade" kualitas generasi muda dengan mempersiapkan masa transisi dari program masa pendidikan ke arah memasuki dunia kerja. (2) Memberikan sebuah pelayanan yang sesuai kebutuhan bagi generasi muda (3) memiliki komitmen yang kuat (4) Memiliki sumber daya yang cukup, serta (5) Memiliki akses jaringan sosial baik virtual maupun personal. Berdasarkan kriteria yang telah ditetapkan sebelumnya maka Youthwin Thorough Economic Participation bekerja sama dengan lembaga pendidikan dan lembaga terkait dengan dunia kerja untuk mengembangkan sebuah kurikulum yang inovatif dan transformatif dengan harapan untuk mememberikan peningkatan pada keterampilan dan keahlian generasi muda ketika sedang membuat keputusan finansial yang tepat sehingga diharapkan di ujungnya mencapai sebuah kesejahteraan finansial individu. Universitas Merdeka Malang merupakan lembaga pendidikan tinggi di kota Malang telah membuat perjanjian kerja sama dengan pihak USAID YEP.

Financial Life Skills merupakan sebuah aktivitas yang terstruktur untuk mengintegrasikan kurikulum bahan ajar finansial dengan keterampilan hidup, dengan tujuan dapat meningkatkan kualitas hidup peserta menjadi lebih bermakna (Rencana Pembelajaran FLS, YEP, USAID, 2017).

Literasi Finansial menurut Regulasi OJK Nomor 76/POJK.07/2016 adalah sekumpulan pengetahuan, keterampilan, dan keyakinan, yang mempengaruhi sikap dan perilaku untuk meningkatkan kualitas pengambilan keputusan dalam memanajemen keuangan untuk mencapai kesejahteraan. Sedangkan literasi keuangan menurut penelitian Lusardi dan Mitchell pada tahun 2007 sebagai sebuah pengetahuan keuangan dan kemampuan untuk mengaplikasikannya pada kehidupan sehari hari. 
Berdasarkan beberapa pendapat disimpulkan Literasi Keuangan sebagai rangkaian aktivitas penghasil untuk meningkatkan kemampuan pengetahuan, keterampilan, kepercayaan diri, sikap, dan perilaku, sehingga bisa memanajemen keuangan dirinya sendiri dengan tepat sehingga dihaapkan dapat meningkatkan kesejahteraan diri maupun orang disekitar. Literasi Keuangan meliputi sejumlah aspek, yaitu pengetahuan dasar keuangan pribadi, pengelolaan uang, pengelolaan kredit utang, menabung dan investasi, serta pengelolaan risiko keuangan.

Soft skills atau ketrampilan Hidup adalah satu paket kemampuan yang mempengaruhi interaksi dengan orang lain. Soft skills memuat komunikasi efektif, berpikir kreatif dan kritis, membangun kelompok, serta kemampuan lainnya yang terkait kapasitas kepribadian personal (Widhiarso, 2009). Ketranmpilan hidup merupakan kemampuan yang berada di dalam diri dan dikorelasikan dengan perasaan manusia. Terdapat gambaran atribut personal yang menggambarkan atribut dari kompetensi hingga moral individu dalam sebuah garis kontinum. Soft skills terletak diantara perilaku individu dan keterampilan manjemen diri. Intervensi yang tepat dalam upaya meningkatkan ketrampilan hidup adalah dengan pelatihan terstruktur atau dengan pembinaan dan pendidikan yang fokus dan intensif.

Model pembelajaran experiential learning yang dikemukan oleh Mahfudin (2011), merupakan sebuah bentuk pembelajaran yang berfokus untuk menciptakan proses belajar yang bermakna, diharapkan peserta pelatihan mengalami dan terlibat langsung dengan apa yang mereka pelajari. Melalui model experiental learning, peserta pelatihan belajar tentang konsep materi serta dilibatkan secara langsung dalam proses pembelajaran untuk dijadikan suatu pengalaman baru yang mendidik. Hasil proses pembelajaran experiential learning memfokuskan bidang kognitif dan subjektif dalam proses belajar. Pengetahuan yang tercipta dari model El adalah persatuan pemahaman danmengubah pengalaman pribadi

Daya Saing adalah keinginan diri agar dapat menjadi juara dalam sebuah persaingan, lebih kompeten dan berprestasi, berusaha menjadi lebih baik dari orang di sekitarnya. Pribadi yang memiliki daya saing tinggi, akan berupaya bekerja lebih optimal dan maksimal, kuat menghadapi berbagai situasi, kondisi, halangan dan dapat beradaptasi dengan lingkungan kerjanya. Menurut Sumihardjo (2008) menyebut daya saing sama dengan competitiveness atau competitive yang berarti daya saing dapat bermakna kemampuan untuk berusaha menjadi unggul atau terbaik dalam bidang tertentu yang dilakukan pribadi, kelompok atau lembaga tertentu.

Tabel 1

Jabaran 14 paket Financial Life Skills

\begin{tabular}{lll}
\hline Modul & Materi & Ringkasan \\
\hline 1 & $\begin{array}{l}\text { Pengantar Soft Skills } \\
\text { dan Financial Skills }\end{array}$ & $\begin{array}{l}\text { Peserta terlibat untuk saling tahu sama lain dan menetapkan } \\
\text { peraturan dasar guna menciptakan lingkungan pembelajaran } \\
\text { yang kondusif dan nyaman bagi peserta. }\end{array}$ \\
\hline 2. & $\begin{array}{l}\text { Membangun Rasa } \\
\text { Percaya Diri, }\end{array}$ & $\begin{array}{l}\text { Membangun keyakinan diri peserta dengan mengidentifikasi } \\
\text { aspek-aspek yang dapat mempengaruhi kepercayaan diri, serta } \\
\text { mengenali orang yang mampu membantu meningkatkan } \\
\text { keyakinan diri. }\end{array}$ \\
\hline 3. & Membangun Sumber & $\begin{array}{l}\text { Menolong peserta untuk memahami kelemahan, ancaman dan } \\
\text { peluang. Para peserta juga bisa mempelajari mengenai faktor } \\
\text { yang bisa menentukan penghasilan dan peran modal insani } \\
\text { terhadap masa kedepannya }\end{array}$ \\
\hline 4. & Menjadi Pribadi yang & $\begin{array}{l}\text { Membantu peserta untuk menemukan pemahaman mengenai } \\
\text { perbanggung Jawab : } \\
\text { perbedaan perilaku yang bertanggung jawab dan tidak dalam } \\
\text { kehidupan pribadi dan kehidupan keuangan. }\end{array}$ \\
\hline 5. & Berpikir Kritis dalam & $\begin{array}{l}\text { Menganalisa biaya dan kegunaan yang di peroleh dari sejumlah } \\
\text { alternatif pilihan solusi sebagai acuan sebelum seseorang untuk } \\
\text { mengambil keputusan yang tepat. }\end{array}$ \\
\hline
\end{tabular}




\begin{tabular}{|c|c|c|}
\hline 6. & $\begin{array}{l}\text { Menentukan Tujuan } \\
\text { Hidup: Pribadi dan } \\
\text { Keuangan }\end{array}$ & $\begin{array}{l}\text { Peserta pelatihan akan mempelajari mengenai fokus penting } \\
\text { menentukan target untuk menolong pembuatan keputusan } \\
\text { dengan hasil yang lebih tepat sesuai dengan target yang telah } \\
\text { daiatur sebelumnya. }\end{array}$ \\
\hline 7. & $\begin{array}{lr}\text { Membuat } & \text { Anggaran } \\
\text { dan } & \text { Mengelola } \\
\text { Keuangan } & \end{array}$ & $\begin{array}{l}\text { Perencanaan yang baik akan membuat tujuan keuangan tercapai } \\
\text { dengan baik. Peserta juga dapat diperkenalkan pada peran dan } \\
\text { tanggung jawab lembaga keuangan dalam mengelola keuangan } \\
\text { pribadi. }\end{array}$ \\
\hline 8. & $\begin{array}{l}\text { Mengatasi Kebiasaan } \\
\text { Menunda Pekerjaan }\end{array}$ & $\begin{array}{l}\text { Memahami dan memanajemen pentingnya prioritas akan sebuah } \\
\text { tanggung jawab, sehingga dapat menuntaskan kewajiban dan } \\
\text { tugas yang penting dan insidentil dimanapun berada. }\end{array}$ \\
\hline 9. & $\begin{array}{l}\text { Merencanakan } \\
\text { Tabungan }\end{array}$ & $\begin{array}{l}\text { Tabungan adalah pilihan antara melakukan pengeluaran atau } \\
\text { menunda untuk di lain kesempatan Peserta juga akan } \\
\text { mempelajari penggunaan peraturan untuk memperkirakan } \\
\text { lamanya proses tabungan agar nilainya menjadi berganda. }\end{array}$ \\
\hline 10. & Kredit dan Pinjaman & $\begin{array}{l}\text { Memahami aspek menjadi debitur yang cerdas yaitu belajar } \\
\text { memenuhi syarat menjadi peminjam yang baik serta } \\
\text { mengidentifikasi perilaku positif dan negatif dari penggunaan } \\
\text { kredit. }\end{array}$ \\
\hline 11. & Komunikasi Positif & $\begin{array}{l}\text { Menfokuskan pada } 3 \text { bentuk komunikasi dan menolong peserta } \\
\text { pelatihan mendeskripsikan bahwa komunikasi asertif lebih efektif } \\
\text { dan efisien daripada komunikasi bentuk agresif atau pasif.. }\end{array}$ \\
\hline 12 & $\begin{array}{l}\text { Skema } \\
\text { Pembiayaandan } \\
\text { Investasi llegal }\end{array}$ & $\begin{array}{l}\text { Mengetahui dan megidentifikasi segala macam bentuk penipuan } \\
\text { keuangan dan investasi bodong. Dan berfokus pada efek risiko } \\
\text { keuangan yang dapat ditemukan dalam kehidupan. }\end{array}$ \\
\hline 13. & $\begin{array}{l}\text { Kerjasama Tim dan } \\
\text { Profesionalisme }\end{array}$ & $\begin{array}{l}\text { Memfokuskan pada prinsip yang dibutuhkan agar memiliki } \\
\text { profesionalisme yang baik diperkuat dengan pemahaman, } \\
\text { keahlian dan keterampilan teknis yang sudah dimiliki oleh peserta } \\
\text { sebelum mengikuti pelatihan. }\end{array}$ \\
\hline 14. & $\begin{array}{l}\text { Membuat Rencana } \\
\text { Aksi untuk Mencapai } \\
\text { Tujuan Pribadi dan } \\
\text { Keuangan }\end{array}$ & $\begin{array}{l}\text { Memainkan "The Wealth Game", Setiap peserta pelatihan akan } \\
\text { diberikan modal awalan dengan nilai tukar yang telah diatur dan } \\
\text { ditetapkan serta berupaya untuk meningkatkan nilai kekayaan. } \\
\text { Hasil permainan akan dijelaskan ke dalam aspek prioritas yang } \\
\text { dapat menentukan kesuksesan hidup, antara lain : kemampuan, } \\
\text { usaha, motivasi, keberuntungan, serta nilai dan cara pandang } \\
\text { tentang,"menolong sesama". }\end{array}$ \\
\hline
\end{tabular}

Sedangkan Pengawasan dan Penilaian Akhir Pelatihan FLS dijabarkan sebagai berikut:

Tabel 2:

Alat Pengawasan dan Evaluasi (Pengukuran) Pelatihan FLS

\begin{tabular}{lllr}
\cline { 2 - 4 } & No. Alat & \multicolumn{2}{l}{ Fungsi } \\
\hline 1 & Profil latar belakang peserta & $\begin{array}{l}\text { Menyeleksi peserta pelatihan, menciptakan } \\
\text { analisis kebutuhan pelatihan dan pembagian } \\
\text { kelompok untuk peserta pelatihan }\end{array}$ \\
\hline 2 & $\begin{array}{l}\text { Penilaian Pra Pelatihan (Pre } \\
\text { Test) }\end{array}$ & $\begin{array}{l}\text { Mengumpulkan penilaian awal atas } \\
\text { pengetahuan dan pemahaman peserta tentang }\end{array}$ \\
\hline 3 & Evaluasi Harian & $\begin{array}{l}\text { Fenilai tingkat kepuasan peserta terhadap } \\
\text { pelatihan tiap hari pelaksanaan }\end{array}$ \\
\hline 4 & $\begin{array}{l}\text { Penilaian Pasca Pelatihan } \\
\text { (Post Test) }\end{array}$ & $\begin{array}{l}\text { Mengumpulkan penilaian awal dari } \\
\text { pengetahuan dan pemahaman peserta tentang }\end{array}$ \\
\hline
\end{tabular}




\begin{tabular}{lll}
\hline & FLS \\
\hline 5 & Evaluasi Akhir Pelatihan & $\begin{array}{l}\text { Menilai tingkat kepuasan peserta terhadap } \\
\text { pelatihan secara utuh baik materi, instruktur } \\
\text { maupun fasilitas penelitian }\end{array}$ \\
\hline 6 & Laporan Pelatihan & $\begin{array}{l}\text { Mengawasi dan menrencanakan tindak lanjut } \\
\text { penelitian untuk kedepannya }\end{array}$ \\
\hline & Sumber: Panduan Pelatih dan Master Trainer, YEP, USAID, 2017 (diolah oleh peneliti)
\end{tabular}

\section{Metode}

Lokasi penelitian berada di Gedung Program Diploma Kepariwisataan Universitas Merdeka Malang jalan Bandung Malang pada hari selasa hingga kamis tanggal 18 - 20 Juni 2019. Penentuan jumlah sampel penelitian dengan sensus berdasarkan pada ketentuan menurut pendapat yang dikemukakan oleh Sugiyono (2014: 61-63), yang menyebutkan bahwa "Sampling jenuh atau sensus adalah metode pengambilan sampel penelitian apabila seluruh anggota populasi digunakan sebagai sampel penelitian. Jadi sampel penelitian adalah seluruh Mahasiswa Peserta Pelatihan Financial Life Skill berjumlah 24 orang. Data yang dikumpulkan dalam penelitian ini ada 2 yaitu berupa data primer dan sekunder. Data primer diperoleh dengan menggunakan kuesioner. Sedangkan data sekunder berupa hasil studi literatur. Untuk analisis data menggunakan uji beda dengan SPSS 22 untuk menguji terdapat atau tidaknya perbedaan rata-rata tingkat pemahaman literasi keuangan dari mahasiswa sebelum dan sesudah terjadinya pelatihan Financial Life Skills.

Hasil Penelitian

Tabel 3. Hasil Uji Beda Rata -rata T-test Pemahaman Literasi Keuangan Soft Skill Sebelum dan Sesudah Pelatihan Financial Life Skill

\begin{tabular}{ccccccc}
\hline Uraian & Rata rata & $\begin{array}{c}\text { Paired Differences } \\
\text { Penyimpangan }\end{array}$ & $\begin{array}{c}\text { Rata2 } \\
\text { Standar Error }\end{array}$ & $t$ & df & Sig \\
\hline $\begin{array}{c}\text { Pemahaman } \\
\text { sebelum dan } \\
\text { sesudah Pelatihan } \\
\text { Financial Life Skill }\end{array}$ & $5.70435 \mathrm{E} 7$ & $2.7542 \mathrm{E} 7$ & $5.4631 \mathrm{E} 6$ & 10.422 & 23 & .000 \\
\hline
\end{tabular}

Sumber : Data primer diolah,

Dari hasil uji beda di dapatkan hasil bahwa signifikansi 0,000 yaitu $P$ - Value $>0,05$, dimana t hitung $>t$ tabel, maka Hipotesis diterima atau terdapat perbedaan nyata pemahaman literasi keuangan sebelum dan sesudah Pelatihan Financial Life Skill.

Tabel 4. Hasil Uji Statistic

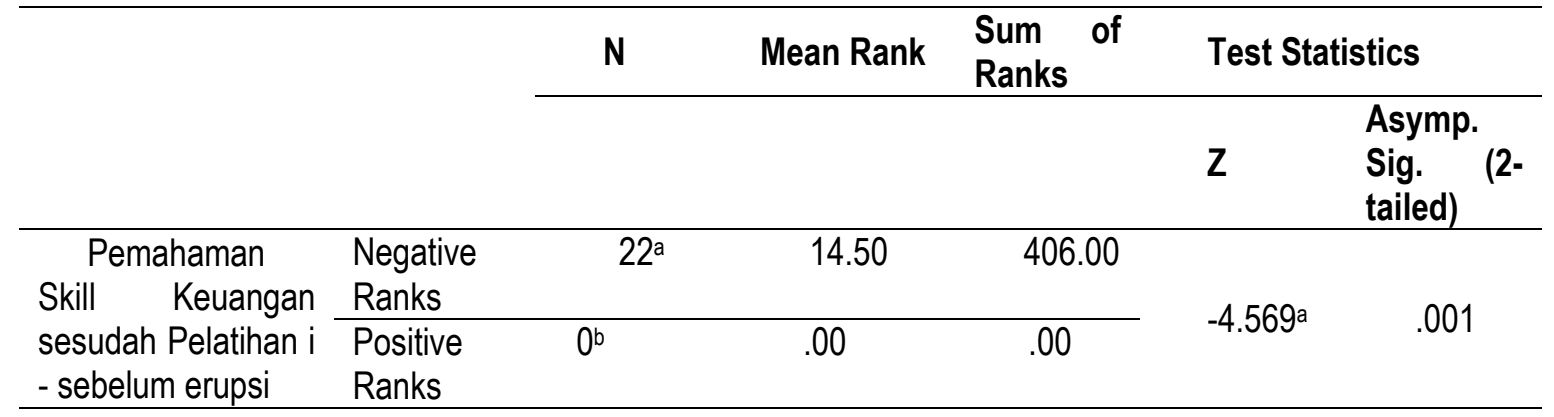




\begin{tabular}{ccc}
\hline & Ties & $2^{\mathrm{c}}$ \\
\cline { 2 - 3 } & Total & 24 \\
\hline
\end{tabular}

Sumber : Data primer diolah,

Dari hasil uji diatas diperoleh hasil yaitu signifikansi dari penelitian adalah sebesar 0,001 yakni lebih kecil dari 0,005. Dapat diambil simpulan yang menyatakan bahwa terdapat perbedaan yang nyata Tingkat Skill Pemahaman Literasi keuangan dan Soft Skill Mahasiswa sebelum dan sesudah Pelatihan Financial Life Skills

\section{Pembahasan}

Dalam penelitian diperoleh bahwa setelah kegiatan uji coba modul pelatihan Financial Life Skills maka pemahaman mengenai kecakapan kemampuan keuangan terdapat perbedaan yang bermakna bahwa terdapat perbedaan rerata pemahaman kecakapan keuangan sebelum dengan setelah perlakuan pada kelompok uji coba modul FLS. Bekerja dengan cara yang inter-professional merupakan konsep lama. Pada literatur keuangan yang profesional, terutama dalam kecakapan hidup sangat jelas nampak manfaat dan tantangan untuk mengintegrasikan tenaga kerja untuk belajar dan menghargai budaya profesi lainnya.

Pelatihan kecakapan hidup merupakan salah satu upaya dalam penambahan pengetahuan dan kemampuan seseorang dengan tujuan untuk mengingat fakta atau kondisi nyata. Dengan cara memberi dorongan terhadap pengarahan diri serta aktif dalam memberikan informasi atau ide baru (Suliha, 2002). Program pelatihan Keterampilan Hidup Berbasis Keuangan merupakan proses mengintegrasikan kurikulum literasi keuangan dan keterampilan hidup, dengan tujuan dapat meningkatkan kualitas hidup. Berikut pendapat mengenai literasi keuangan dan keterampilan hidup.

Ada beberapa sebab seseorang yang telah memperoleh pengalaman tetapi sulit diingat, Seseorang cenderung lupa karena tergantung pada sesuatu yang diamati, situasi dan proses pengamatan berlangsung serta waktu (Purwanto, 1990). David Kolb (1984) berpendapat bahwa pengetahuan sebagai hasil dari proses belajar sangat dipengaruhi oleh waktu sejak memperoleh pemaparan. Ada beberapa faktor yang memengaruhi pengetahuan seseorang yakni pendidikan, Informasi, budaya, Pengalaman dan Sosial Ekonomi (Notoatmodjo, 2007).

Hasil penelitian didukung oleh teori yang dikemukakan oleh Atkinson dan Shiifrin (1968) menyatakan bahwa semakin lama informasi dipertahankan dalam memori jangka pendek dengan bantuan pengulangan, semakin besar kemungkinannya untuk masuk ke memori jangka panjang, sehingga relative menjadi lebih permanen. Pengetahuan akan disimpan lama dalam memori jika dilakukan pengulangan dengan mengingat kembali pada saat dibutuhkan. Pendidikan FLS penting untuk menunjang soft skill yang lain. Pendidikan merupakan „behavioral investment" jangka panjang. artinya pendidikan kesehatan baru dapat dilihat beberapa tahun kemudian. Dalam waktu yang pendek (immediate impact) pendidikan kecakapan hidup hanya menghasilkan perubahan atau peningkatan pengetahuan mahasiswat. Pengetahuan hasil pelatihan FLS akan berpengaruh pada perilaku sebagai hasil jangka menengah (intermediate impact) dari pendidikan Kecakapan hidup. Penelitian ini masih memiliki keterbatasan yakni jumlah responden yang masih terbatas dabn belum bisa mewakili seluruh mahasiswa universitas merdeka Malang, sehingga hasil penelitian belum mampu menggambarkan kemampuan finansial mahasiswa secara umum.

\section{Kesimpulan}

Dari hasil penelitian ketrampilan hidup dapat diambili simpulan bahwa gambaran umum soft skills mahasiswa tergolong baik, yang dapat diartikan mahasiswa Universitas Merdeka Malang mempunyai ketrampilan hidup yang baik untuk menunjang kesuksesan peserta pelatihan dalam studi atau pekerjaan peserta di masa depan. Berdasarkan hasil penelitian dapat pula dilihat terjadi perbedaan yang nyata antar sebelum dan sesudah pelatihan Finansial Life Skill. Hal ini menunjukkan pentingnya pelatihan Financial Life Skill guna meningkatkan daya saing lulusan Universitas Merdeka Malang. Mahasiswa sangat perlu memiliki skill atau 
pengetahuan di bidang literasi (sadar) keuangan sehingga saat lulus dan menjadi pekerja, mereka mampu mengelola keuangan dari gaji atau pendapatan mereka secara baik dan tepat.

\section{Referensi}

Arikunto, S. 2013. Prosedur Penelitian Suatu Pendekatan Praktik. Jakarta : Rineka Cipta

Atkinson, R. C., \& Shiffrin, R. M. 1968. Human memory: A proposed system and its control processes. The psychology of learning and motivation: Advances in research and theory, 2, 89-195.

Kolb, D, A. 1984 Experiential Learning Experience as The Source of Learning and Development. New Jersey: Prentice Hall.

Lusardi, A dan Mitchell, 0.2007. Financial Literacy and Retirement Planning: New Evidence from the Rand American Life Panel, 2007 MRRC Working Paper 157.

Mahfudin. 2011. Model pembelajaran experiential learning. Tersedia http://albyjmahfudz.blogspot.com/2011/05/model-pembelajaranexperiential html diakses 19 Juni 2019

Notoatmodjo S. 2007. Pendidikan dan Prilaku Kesehatan. Jakarta: Rineka Cipta. Peraturan Otoritas Jasa Keuangan Nomor 76/POJK.07/2016

Purwanto MN. 1990. Psikologi pendidikan. Remaja Rosdakarya

Sugiyono. 2014. Metode Penelitian Pendidikan Pendekatan Kuantitatif, Kualitatif, dan R\&D. Bandung: Alfabeta.

Suliha, Uha. 2008. Pendidikan kesehatan dalam keperawatan. Jakarta: EGC

Sumihardjo, Tumar. 2008. Daya Saing Berbasis Potensi Daerah. Bandung : Fokusmedia

YEP USAID (United States Agency for International Development), Local Governance Support Program (LGSP) USAID, Jakarta, Bahan ajar 2017.

Widhiarso, W. 2009. Evaluasi Soft Skills dalam Pembelajaran. Melalui http://widhiarso.staff.ugm.ac.id diakses 19 Juni 2019 